\title{
The Intersection of Pedagogical Documentation and Teaching Inquiry: A Living Curriculum
}

\author{
Margaret MacDonald and Cher Hill
}

\begin{abstract}
Using interpretive research methods, this paper examines the use of pedagogical documentation (PD) as a storied method of assessment and inquiry by in-service K-3 teachers. Our findings show that PD is highly effective in opening "reflective space" for primary teachers and children aged five to eight and inviting co-inquiry to deeper pedagogical examination and interpretation of learning. The intersection of $\mathrm{PD}$ as a storied approach to evaluation and in teacher inquiry was implemented in a variety of ways as teachers adapted PD to meet their communal needs and address their professional goals. We conclude with a discussion of the power of digital images in learning stories and inquiry.
\end{abstract}

\section{Background}

As a follow-up to an article written over 10 years ago (MacDonald, 2007) on the use of pedagogical documentation in early primary classrooms in the lower mainland of British Columbia, this paper discusses the current use of PD as a storied method of assessment among primary teachers. In this research article, we investigate kindergarten and grades 1, 2, and 3 teachers' use of pedagogical documentation to inform self-generated inquiry questions posed by teachers who are enrolled in our Learning in the Early Years (LEY) Graduate Diploma in Education (GDE). ${ }^{1}$

Pedagogical documentation has been widely used in the project approach of the Reggio Emilia preschools in Italy and globally and by teachers in other preschools serving infants, toddlers, and threeto five-year-olds (Buldu, 2010, Grieshaber, \& Amos Hatch, 2003; Knauf, 2015, Rintakorpi, 2016), and is now beginning to be incorporated more widely into North American primary classrooms (K-3) (Wien, Guyevskey, \& Berdoussis, 2011) and requires further examination in these contexts. It also requires further investigation in its use as a storied from of anecdotal reporting and as a method to dialogue with parents through narrative forms of reporting.

The Reggio Emilia style of documentation has been used to document kindergarten, primary, and early childhood classroom projects in Canada and the U.S. (Cadwell, 2003; MacDonald, 2007; McLellan, 2010; Stacey, 2015; Wein, 2008,) to scaffold children's memories of activities taking place once per week (Fraser, 2011; Hunt, Nason, \& Whitty, 2000), and to develop a co-constructed, emergent curriculum (Abramson, 2006). Teachers' anecdotes also describe successes in documenting the development of individual children (Giovannini, 2001) and the value of documentation in inclusive settings when assessing children with support needs (Vakil, Freeman, \& Swim, 2003). Little is known 
however about precisely how teachers are using PD in primary classrooms, particularly its affordances as a storied method to help teachers reflect on their own action within practice for professional learning.

\section{Pedagogical Documentation}

In theory, through a narrative approach, pedagogical documentation illuminates participants' interests, skills, ideas, and theories (Edwards, Gandini, \& Forman, 1998; Giovannini, 2001; Giudici, Rinaldi, \& Krechevsky, 2001). It has been defined by Dahlberg, Moss, and Pence (1999), as both content and process and consists of a collection of teacher observations and other digital traces and/or artifacts of learning collected during dedicated learning activities and/or play (e.g., photographs, video segments, children's comments, products that have been created by the children, and teacher interpretations of learning). Importantly, this content can also be viewed and discussed with students "in process" to deepen teachers' understanding and interpretation of student learning and their own teaching. It may also help communicate interests, skills, and ideas as teachers and their students co-construct next steps in curriculum or project planning. In theory, when PD is shared with the children (and families), teachers are able to perceive the significance of the classroom learning and interests and can focus on, repeat, or further it. If this method becomes proprietary in the classroom by becoming part of a sustained teaching practice where teachers are using PD to engage in cycles of inquiry, it can potentially assist teachers and students in better understanding learning moments (both the teacher's and student's), group process, classroom discourse, or any number of authentic questions that emerge from the curiosities, deep questions, or contradictions that present themselves to teachers or students. It can also take into account students' funds of knowledge (Gonzalez, Moll, \& Amanti, 2005; Moje et al., 2004), unique dispositions, interests, creativity, humor, and so forth, and work at re-representing student and teacher learning in meaningful ways.

Intersections between pedagogical documentation and teacher inquiry. Pedagogical documentation appeared to be a useful method for the teachers enrolled in our graduate diploma program, which is based on a teacher inquiry methodology. In this approach the teacher engages in a systematic, intentional study of his or her practice (Cochran Smith \& Lytle, 1993; Fichtman Dana \& Yendol-Hoppey, 2009). Both pedagogical documentation and teacher inquiry are based on a similar core assumption that all members of the classroom community should be empowered as teachers and learners (Cochran Smith \& Lytle, 2009). While teaching in the LEY program, the first author (Margaret) observed a close connection between teacher inquiry and student inquiry (Brancombe, Goswami, \& Schwartz, 1992; Butler \& Schnellert, 2008; Cole \& Knowles, 2000). This occurred as teachers began to engage with the use of Pedagogical Documentation. When using PD, our students (K-3 teachers) were learning about their students (K-3 children), their curriculum, as well as about themselves and their practice. We posited, therefore, that there was a concomitance between teacher inquiry and student inquiry when using PD and that this interface between teacher inquiry and Pedagogical Documentation merited further investigation.

Our investigation. Given its potential to connect students and teachers through inquiry, PD was directly taught beginning in the first semester and reinforced across each successive semester through examples 
and collaborative discussions of in-process work and student-led presentations of their own PD. We observed diverse forms of PD implementation when reviewing teachers' learning portfolios. This led to the following question forming the basis of the present investigation:

How is the method of Pedagogical Documentation implemented by elementary school teachers within an inquiry-based Graduate Diploma Program?

\section{Research Context}

Our program focus and goal within the Learning in the Early Years and other diplomas offered through Field Programs at Simon Fraser University is to be as responsive as possible to the professional development needs of in-service teachers in the province while adhering to a core pedagogical belief in Teacher Inquiry as a method of pursuing self-directed questions related to pedagogical practice. To this end, a parallel structure of nongraded discipline-specific content and theory (two or three credits) is taught in conjunction with a nongraded field study or teacher inquiry course (two or three credits) over a 30-credit six-semester program. To enroll in the program, teachers must be working in the classroom so that the content or focus of each graduate diploma can be supported by reflexive practice through inquiry into their own practice. Many of the course capacities in the Learning in the Early Years Graduate Diploma promote the development of relationships and collaboration among teachers in the cohort and between teachers in the cohort and their K-3 students. The focus of the Learning in the Early Years program is also on the development of emergent and responsive curriculum that allows activities and projects to emerge from the children or teachers' interests or from sources like: the child's own developmental tasks and challenges, the built and social environment (including materials), unpredictable and spontaneous events (i.e., challenges, conflicts, and opportunities of living together) and, importantly, the values held by the school and communities (Jones, 2012).

\section{Methodology and Participants}

This investigation is part of a larger study into the teacher inquiry methodology in our teacher professional development program unit (Field Programs) at Simon Fraser University, in British Columbia, Canada. The larger study, informed by grounded theory research design (Charmaz, 2005; Corbin \& Strauss, 2008) has led to this related investigation using interpretive research methods (Schwartz-Shea \& Yanow, 2012; Smith, 1992; Radnor, 2002) to better understand primary teachers' use of PD. Our approach to data collection and analysis has been iterative and ongoing, shaping data collection and focusing our understandings as the project progresses. Throughout this investigation we have therefore made utmost use of collegial discussion, observation, memos, and member checks for verification of the emerging understandings of our instructional team of teacher educators participating in the project and our students (in-service teachers).

The cohort selected for this study included 39 female students made up primarily of in-service kindergarten teachers (23), two K/Grade 1 teachers, eight grade 2 or 3 teachers, one Learning Assistance/ Resource Room teacher, and five Teachers-On-Call who specialized in primary and/or elementary 
on-call work. With respect to teaching experience, 15 students had between six and 10 years teaching experience, while seven had 11 to 15 years' experience and five had 15 or more years of classroom teaching experience. Of the 39 students, 12 were in early stages of their career with six having between two and five years of teaching experience and six having less than two years.

\section{Data Collection and Analysis}

Our data sources included the portfolios of 13 students that we collected after receiving their written informed consent at the completion of each semester. Although the diploma program is nongraded, the students' reflective practice and field study write-ups are evaluated for content and completion and examined at the end of each semester by way of portfolios. This portfolio is a self-directed collection of their learning and stands as a synthesis of the students' field study, discussions, readings, and class activities. It often includes a variety of photos, graphics, and narrative forms of representation. These portfolios therefore are important artifacts representing student engagement with the course content and inquiry and formed the basis of our investigation into pedagogical documentation.

Rich anecdotal evidence was collected in the fourth semester of the program, suggesting the power of "in-process" documentation where teachers viewed photos or video clips with the children, engaging them in discussion and to aid in verification and interpretation of their understandings of the children's intensions, thoughts, and/or theories. This complex interaction between the children and classroom teacher was powerful, in that it allowed the in-service teachers (our students) to reflect on the meaning that the learning activities or engagement held for their students and for themselves as pedagogues.

In addition, ongoing formal and informal discussions and observance of PD across the entire cohort were used, as was a semi-structured focus group interview to further our understandings about the teachers' use of PD and "in-process documentation." The focus group discussion was held with 10 participants from this cohort who were in the final semester of their GDE (see Appendix A for focus group questions). This group was selected according to geographical convenience, but represented a diverse sampling of in-service teachers: (two) Kindergarten French Immersion; (one) Grade 2 French Immersion; (one) Teacher on Call; (one) resource room teacher; and (five) Kindergarten (English Language teachers), all of whom were members of one mentor group. The discussion from the focus group was recorded and transcribed so that we could review and analyze the content. In vivo coding methods were used, where the words or short phrases of the participants were adopted as the code to capture student voice (Saldana, 2009).

Through our own discussion and reflective analysis, we began to consider the "in-process" work of these teachers as the creation of "space for pedagogical reflection." We were then able to generate a provisional hypothesis: that teacher reflection is mediated by the type of subjective-objective stance they take in their field study, that is, how they positioned themselves in relation to their students (e.g., as an objective observer, a co-constructor, or an independent interpreter of events). This hypothesis was later verified and deepened with our teacher participants. Throughout this process, data were collapsed and reduced through discussion between researchers (Margaret and Cher), notes, and conceptual memos that 
took into consideration contextual factors and intervening conditions determined by the portfolios and later verified in the focus group interview.

\section{Our Findings}

As teachers implemented PD into their field studies, they experimented with group size (individual, small group, full class), methods of documentation (photographing, audio recording, video recording, note taking and/or transcription), and presentation (document boards, class meetings, school-based websites) in order to adapt PD based on their needs and contexts, and then reflected on the outcomes. Although at times it was challenging given the student-teacher ratio in elementary schools and the limited technology available to the teachers, over time they were able to develop meaningful processes, and viewed their LEY and school learning community as vital in enabling them to implement PD within their contexts. As discussed by our in-service teachers:

J: because I'm a talker I kind of like having someone go through the same process as me. I like having ideas and be[ing] able to bounce ideas off, and being able to talk about what I'm thinking and what's not working or if I've hit a wall. I can't imagine trying to figure out documentation by yourself in a classroom. I think it's good to bring it to a group.

A: Absolutely, having someone telling you what to do or try is an avenue ... but unless you have peers who are doing it as well, you just kind of go, "oh my gosh it's not working." S: And then you see what others come up with ...

A: And then you can feel better...

J: It encourages you to keep trying. Because when I was doing it and I couldn't get the transcription down I thought "this is brutal"...but being able to chat with other people and know that they were having the same struggles ... It makes it a lot easier.

While we were pleased that our program produced such a culture, we are concerned about the sustainability of these practices once the teachers complete their formal education. Moreover, we wonder how we can best support our teachers to continue to participate in these networks.

We found that pedagogical documentation was used purposefully and in multiple ways as these in-service teachers reflected on the needs of the members of their learning community, as well as on their own professional goals. The documentation practices associated with pedagogical documentation and related documentation methods, such as learning stories, where the teacher presents a narrative describing the meaning of the learning moment and the future opportunities and possibilities it holds ${ }^{2}$ (Carr, 2001; 2011), were adapted by the teachers in different ways to achieve different ends. 
These adaptations, which are explored in greater detail below, were often intentional, driven by teachers' goals, and characterized by reflection, as teachers responded to situational constraints and/or the evolving teaching and learning environment. As one teacher noted,

It has to be purposeful really. Here am I trying to communicate with the parents? Or am I trying to move the children's learning forward. So trying to be purposeful with it but also being open ended enough to reflect on it and go where the children want to take you.

Based on the portfolio and interview data, there appeared to be four predominant ways in which teachers used Pedagogical Documentation, including: Pedagogical Documentation as a window, PD as catalyst to facilitate co-inquiry, PD as a medium of communication, and PD as a mirror to provide objective evidence. These different practices involved various subjective-objective stances, and led to different implications for pedagogical relationships and transformation of practice.

\section{Pedagogical documentation as a window: "When you are documenting you are listening". ${ }^{3}$} The documentation process generated insights into the students' thinking, interests, and strengths, and enabled teachers to adapt their practices accordingly. As one teacher documented in her portfolio, "The documentation I have gathered lets me listen to the students' thinking, something that I would normally never be privy to." During the focus group, teachers talked about how the documentation process allowed them to identify the strengths and needs of all their students, even those with behavioral challenges, as well as those who rarely vocalize their thinking. Teachers then used these insights to guide their practice.

When you do that deep listening ...(y)ou can hear what their questions are and where they want to go with their learning and where you could now bring in some provocations and see what they take up and [identify] a place to start where they are at.

This type of "deep listening," or "attending to children with care," as Carini (2000) might call it, inherent in pedagogical documentation, involves a nontraditional research stance in which the knower is not an objective observer, but is aware of his or her own subjectivity, attempts to bracket assumptions; that is, tries to first identify his or her assumptions in any given situation and then see past them (ignoring them if necessary) to better engage with the perspective of the other. This stance enables teachers to see students in more complex ways, focusing on strengths rather than weaknesses, and to engage in more responsive and ethical practice.

This nontraditional research stance helped to disrupt traditional power relationships where the teacher is expected to be the only curriculum expert; however, students' roles as active co-constructors of knowledge were still limited. Without sharing and discussing data with students, teachers' understandings are limited to their own interpretations of events. For some teachers, this process of attending with care and deep listening to students might be the first step towards more complex collaborative practices afforded by pedagogical documentation. As one teacher noted in her portfolio, after experimenting with this method for the first time, 
I know I need to change how I've been using [pedagogical documentation], particularly in the area of parental involvement and evidence display. It has been beneficial for me so far, and now I need to broaden that and involve the parents, my colleagues and even the students more.

\section{Pedagogical documentation as a catalyst for moving learning forward: "Go where the children want} to take you." Some teachers used pedagogical documentation to not only inform their understandings of thinking and learning, but also to facilitate co-inquiry with students. Classroom photos, videos, transcripts, and the like were used as common reference points to further discussions, reflections, questions, and elaborations. Through these discussions learning was deepened as members of the classroom community were pushed forward in their thinking and curriculum was co-constructed by teachers and students. For example, one teacher documented a group of students role-playing motherbaby relationships. Initially, their play was restricted to crying "babies" and frustrated "mothers," and did not progress or deepen over a period of months. The class's examination of the photos of their play led to a discussion about the different roles of various members of families. The class then developed a list of questions that they had about babies, and the teacher invited a mother and baby to visit the class. The students asked the mother their questions and observed interactions between the mother and baby. After these experiences, the students' play "completely shifted." As she noted,

... they realized that babies don't only cry and that there are other things that they can do. I think that experience was really powerful for them.... I had the photos of them playing after and before and you can see the change just in a still photo and then when I took it back to them, the 'moms' were really pleased because the 'babies' were finally listening.

In other similar situations where pedagogical documentation of students' learning was shared within the class, these artifacts became a communal resource that supported the learning of others in the classroom community. For example, one teacher described a project in which she documented students' constructions of elaborate block cities. Students were then asked to arrange the photos of their projects in order, revisit their work, and present their learning to the class. The teacher reported that sharing the documentation "got things going for other kids who went on and wanted to reproduce and even extend what they wanted to do."

In another case both the teacher and students were learning new information as they investigated a project on space (an inquiry that was teacher facilitated and student generated). The teacher admitted this was a new topic for her and the fact-finding for both this teacher and her students was authentic. In this example the teacher notes,

we would sit down at our daily meeting and show the pictures and I would say "what is this person doing?" and it was all to do with our space project and then on the back I would just scribe what the answers were ... I found that really powerful and really helpful to put together the panel in the end that showed the whole development of the project to find the provocations to push forward... [it was] much more conversational, it was much more natural. Because it was a project that we were all involved in, it was a whole class project we were all really enthusiastic about it, it made it a lot easier because we could all have a group discussion about it.

Sharing pedagogical documentation with students and engaging in collaborative reflection shifts the traditional teacher-student hierarchy to a more ethical egalitarian relationship and establishes students 
as knowledge producers and agents in their learning. In our focus group discussion, one teacher commented on this egalitarian relationship that could be best described as co-inquiry, noting,

The documentation, in particular in-process documentation, is how you get the kids to step up to the plate as teachers as well. And not just co-creators but actual peer teachers. Through my project in the fall, one of the most amazing things that came out of it was ... not only that the kids saw each other as the expert but they got to see themselves and realized 'hey I have skills that I didn't necessarily know I had and, hey I am an expert at [what] ever it was, and so yah you can come and ask me when you need help doing this' and that's kind of how it helps them take ownership of their learning too.

In these examples their co-inquiry involves a subjective-objective stance in which teachers and students are jointly influencing the learning while simultaneously being influenced by the perspectives of others. Co-inquiry occurred in diverse ways within this cohort and was sometimes initially teacher-led and at other times student-initiated. Importantly, with a few exceptions, we found that most of the examples of co-inquiry described by students in the Learning in the Early Years cohort using pedagogical documentation seemed to involve parallel or perhaps intersecting inquiries (Fichtman Dana \& YendolHoppey, 2009), in which teacher and students pursued relatively separate lines of inquiry, rather than shared inquiries. This we found to be inconsistent with Heron's conception of Cooperative Inquiry (Reason, 2002), which guided our initial understandings of what collaborative inquiry might look like in educational settings, where all members of the community were engaged in the same topic of inquiry. As evident in the mother-baby role-playing example, while all members of the classroom community were engaged in inquiry, and jointly determined the direction of the learning, they were not necessarily learning the same things. The students learned about babies, and the teacher in this example learned about her students' interests and assumptions. This demonstrated an ability on the part of this in-service teacher (our student) to use PD as a reflexive device to bend the learning back onto herself and move not only her students' learning forward, but also her own.

3. Pedagogical documentation as a medium of communication: "Making the learning visible." Teachers used Pedagogical Documentation, raw, or in-process documentation, ${ }^{4}$ as well as Learning Stories (Carr, 2001; 2011), to facilitate communication with parents. In the third semester of the program, the program development team was surprised to discover that an instructor had introduced the students to Learning Stories as an alternative to PD. Learning stories differ from pedagogical documentation in that PD features the voice of the students, highlighting their thinking, questions, and interpretations; whereas Learning Stories typically feature the voice of the teacher and represent his or her interpretations. This unplanned event changed the course of our examination of PD, but yielded some additional understandings about how adaptive our in-service teachers were in applying various assessment methods when communicating with parents. In this case, the teachers gravitated toward the use of Learning Stories rather than PD when they wanted to share with parents what students were doing in the classroom, how students' thinking was progressing, or to communicate their own values, expertise, and perspectives (e.g., to demonstrate to parents why outdoor play is important). Alternatively, they gravitated towards PD when they wanted to share emergent curriculum activities or project-based learning as in the example of the mother and baby play or the classroom study of astronomy. The teachers' use of learning stories took 
on a heightened significance during the 2011/2012 school year when British Columbia public school teachers engaged in job action that included not writing report cards.

Using combinations of Learning Stories and Pedagogical Documentation to make students' learning visible to parents appeared to be very successful. Teachers reported that parents were particularly receptive to, and appreciative of, both forms of communication. For example, one teacher created a 30-minute video documenting students' learning, and even though parent attendance at school events was typically very low in her community, 17 parents out of 22 attended the screening. Although some merits of report cards were discussed, overall, teachers felt that pedagogical documentation and learning stories were more meaningful to parents, more child centred, and more current than report cards, and were therefore, a more ethical assessment practice. As one teacher noted, "I think it's more honest, I think it's more accurate, I think it's more valid, I think it's interesting, the parents can understand it." It was also felt that sharing these various forms of documentation with parents helped to strengthen the home-school connection.

Teacher 1: Don't you think this type of documentation also brings the families in whereas the report cards...

Teacher 2: Pushes them out!

While the communication of learning stories and PD was typically more unidirectional_-from teacher to parent-some teachers shared this form of documentation in hopes of stimulating a dialogue. For example, one teacher posted learning stories on a blog and encouraged parents to comment on all documentation, not just the ones involving their child. Another teacher encouraged parents and their children to talk about the documentation she sent home in hopes that continued conversation with others would take students deeper into the learning.

All that stuff ... would go home to the parents, sort of extending it at a higher level where they can learn to take it upon themselves to write down their own thoughts and share with others and connect with the parents.

4. Pedagogical documentation as a mirror: "It's hard to dispute raw data." Although less frequently discussed, some teachers used in-process pedagogical documentation to draw attention to, and better understand, behaviors of self and other. In this way the video recordings and photos were used to draw children's attention to aspects of their behavior that was visible to others, but perhaps not visible to the individual. One teacher documented a student "throwing a fit in the classroom" and showed the documentation to the child. She also engaged the class in an activity to address the behavior (and the impetus for the behavior: problems with sharing) and she continued to document related positive behaviors for the class to learn from and monitor their growth as a whole. In confidence, the documentation of the individual child was also shared with the child's parent. The teacher concluded,

If I [didn't] have a video the mom would probably not believe what [the] teacher is saying. But with the video she believed it ... so the documentation really helped to make that situation 
visible to the mom so we're ... talking to each other almost everyday about how he is improving at home and how he is improving also in school.

This use of pedagogical documentation alarmed us because it was not inquiry focused and seemed to contradict our students' use of Pedagogical Documentation as a window, where the teacher is engaging in deep listening and attempting to take the perspective of the child. Instead this use involved an objective stance that had never been reflected in demonstrations, readings, or artifacts viewed by the cohort. Our assumption had been that PD would be used to heighten and make students' aware of their engagement in learning and highlight positive interactions to further socially sanctioned behaviours. As instructors, we never imagined that PD (in this form) would be used to highlight negative behavior. In the form used by this teacher, the video was shared with the parent and child to provide a neutral, credible form of evidence. This struck us as being a powerful and potentially destructive and controversial use of Pedagogical Documentation (see Tarr, 2011, for a discussion of ethical issues in the use of Pedagogical Documentation). However, as argued by the teacher, these types of sharing practices have the potential to guide development by bringing an awareness to the child and parent of appropriate behaviors and reflecting on those less desirable ones. We, however, maintained our reservations about documenting this moment and showing the video to the child given the potential to accentuate negative forms of behavior that could be damaging to children's self-image. We had similar reservations about showing the video to the parent, again given its potential to highlight negative rather than positive behavior and precipitate defensiveness on the part of the parent. As Tarr (2011) notes, pedagogical documentation communicates to students how the teacher perceived them, and in this regard, teachers must take great care in selecting which images to share with students. In this case we were impressed by the teachers' care in communicating the behavior in confidence with the child and parent and with her follow-up, intervening and providing the child with subsequent images that could then move the learning forward and strengthen the community through dialogue with the parent, child, and class. Admittedly, we also knew little of the relationship that existed between the teacher and this parent and the history of the child in the class. This example highlights the power of teachers, who hold the mirror to perpetuate or disrupt negative images of children and contribute to positive constructions of learning moments. This example also draws attention to the fact that, unlike other professionals, teachers' expert opinions may be questioned, and supportive documentation may be necessary to initiate conversations between teachers and parents.

\section{Conclusion}

Primary teachers in the Learning in the Early Years Graduate Diploma were found to use pedagogical documentation in different ways to attend to children's interests and experiences, reflect on both their own and their students' learning moments and meaning making, and share ideas and events within the community. The inquiry process, experimentation with practice, and the support of the teachers' own learning community were vital in enabling teachers to adapt PD in meaningful ways within the elementary school context. 
Anecdotal evidence verified through coding of student portfolios and a focus group interview showed that when these teachers actively shared documentation with their students "in process," it not only served as a powerful way to better understand, socially support, and mediate learning, but it also became a means to promote dialogue between members of the learning community. Such ethical encounters can disrupt and slow down the instrumental and mechanical cycle of teaching and learning and lead to transformative practices such as co-inquiry and deep listening that, as suggested by Cochran-Smith and Lytle (2009), establish "new collaborative relationships [that] replace older expert-novice models of proficiency, and [where] new multifaceted goals replace the singular pursuit of best practice" (p. 144). We noted that when teachers had the goal of authentic collaboration in mind and were actively engaged with children during discussions of "in-process" documentation, learning was co-constructed and moved forward under more egalitarian and authentic conditions.

It is important to note that the teachers in our sample were in the early stages of incorporating PD within their practice. Furthermore, as they become more comfortable with this intersection between inquiry and pedagogy, they might shift from more private (e.g., PD as a window) to more public (e.g., PD as a medium of communication or PD as a catalyst) implementations. Discussions of in-process documentation with students and sharing documentation with colleagues and/or parents may be difficult for teachers because it disrupts traditional teacher/student roles and involves a greater extent of vulnerability and risk taking, as teachers expose their own thinking, assumptions, and uncertainties. Teachers may increasingly incorporate these aspects of PD as they become more comfortable with their shifting identities and roles.

When implemented within an inquiry-based graduate diploma program, the practices surrounding the uses of pedagogical documentation were not static and continued to evolve as they are adapted and developed by the teachers in local contexts and under various conditions. Our own practices of supporting the teachers in our graduate diploma program as reflexive inquirers and "pedagogical bricoleurs" facilitate this process, and contribute to our own ethical practice. The teachers saw various forms of PD and Learning Stories as a "genre" that could be constructed for various purposes and audiences. Learning Stories were beneficial in conveying learning to parents and provided strong evidence of competencies while in-process Pedagogical Documentation had greater appeal for use with children and colleagues, particularly when used to move learning forward and develop emergent or responsive practices. Overall, teachers appeared sensitive to the various needs of the constituent groups. Evidence that the teachers were appropriating and adapting PD to meet their needs and suit their particular contexts indicated that we were successful in our efforts to empower teachers to act as teacher inquirers - rather than technicians - and evolve methods in ways that appeared to serve their purposes. However, clearly there are limits to the extent of agency students of PD should have in order to reinterpret curriculum as we noted in one student's use of PD to provide supportive "evidence" of misbehavior. As Brown and Campione (1996) have asserted, adopting surface activities of pedagogical methods, without understanding the principles underlying the specific practices, can in some cases lead to "lethal mutations." In this regard, it is essential that teachers assume an inquiry stance rather than surveillance stance when adapting PD. 


\section{Notes}

1. As teacher educators and researchers, we refer here to in-service teachers as our students. These K-3 teachers are enrolled in a University Graduate Diploma Program called "Learning in the Early Years."

2. Parents are often invited to add comments and responses to the teacher's narrative about the child's exploration and engagement. Learning stories were introduced by one of the instructors in the play course as a possible alternative to PD, but was not intended in the original design.

3. Quotations were drawn from focus group transcripts, and along with the metaphor, are used to summarize each form of implementation.

4. As described earlier, "Raw" or "In-process documentation" refers to bringing the documented photos, transcripts, or activities back to the community of learners (children, parents, other teachers) for discussion and dialogue prior to final write-up. This is an important part of the PD process that allows multiple perspectives and interpretation of learning.

\section{References}

Abramson, S. (2006). Documentation communication action: Co-inquiry meetings for facilitated interchange. Co-Inquiry Journal, 1(1), 1-14. Retrieved from http://www.coinquiry.org/coinarticles.html

Brancombe, N.A., Goswami, D., \& Schwartz, J. (Eds.). (1992). Students teaching, teachers learning. Portsmouth, NH: Boynton/Cook.

Brown, A.L., \& Campione, J.C. (1996). Psychological theory and the design of innovative learning environments: On procedures, principles, and systems. In L. Schauble \& R. Glaser (Eds.), Innovations in learning: New environments for education (pp. 289-325). Mahwah, NJ: Erlbaum.

Buldu, M. (2010). Making learning visible in kindergarten classrooms: Pedagogical documentation as a formative assessment technique. Teacher and Teacher Education, 26, 1439-1449.

Butler, D. L., \& Schnellert, L. (2008). Bridging the research-to-practice divide: Improving outcomes for students. Education Canada, 48(5), 36-40.

Cadwell, L. B. (2003). Bringing learning to life: The Reggio approach to early childhood education. New York, NY: Teachers College Press.

Carini, P. (2000). A letter to parents and teachers on some ways of looking at and reflecting on children. In M. Himley \& P. Carini (Eds.), From another angle: Children's strengths and school standards (pp. 56-64). New York, NY: Teachers College Press.

Carr, M. (2001). Assessment in early childhood settings: Learning stories. London: Paul Chapman.

Carr, M. (2011). Young children reflecting on their learning: Teachers' conversation strategies. Early Years: An International Journal of Research and Development, 31(3), 257-270.

Charmaz, K. (2005). Grounded theory in the 21st century: Applications of advancing social justice studies. In N. K. Denzin \& Y. S. Lincoln (Eds.), Handbook of qualitative research (3rd ed., pp. 507-535). Thousand Oaks, CA: Sage Publications.

Cochran-Smith, M., \& Lytle, S.L. (1993). Inside/Outside: Teacher research and knowledge. New York, NY: Teachers College Press. 
Cochran-Smith, M., \& Lytle, S.L. (2009). Inquiry as stance: Practitioner research in the next generation. New York, NY: Teachers College Press.

Cole, A. L., \& Knowles, J. G. (2000). Researching teaching: Exploring teacher development through reflexive inquiry. Needham Heights, MA: Allyn \& Bacon.

Corbin, J., \& Strauss, A. (2008). Basics of qualitative research. Thousand Oaks, CA: Sage Publications.

Dahlberg, G, Moss, P., \& Pence, P. (1999). Beyond quality in early childhood education and care: Postmodern perspectives. London: Falmer Press.

Edwards, C. P., Gandini, L., \& Forman, G. (Eds.). (1998). The hundred languages of children: The Reggio Emilia approach to early childhood education. Norwood, NJ: Ablex Publishing.

Fichtman Dana, N., \& Yendol-Hoppey, D. (2009). The reflective educator's guide to classroom research: Learning to teach and teaching to learn through practitioner inquiry. Thousand Oaks, CA: Corwin Press.

Fraser, S. (2011). Authentic childhood: Experiencing Reggio Emilia in the classroom (3rd ed.). Toronto, Ontario: ITP Nelson.

Grieshaber, S., \& Amos Hatch J. (2003). Pedagogical documentation as an effect of globalization. Journal of Curriculum Theorizing, 19(1).

Gonzalez, N., Moll, L.C., \& Amanti, C. (2005). Funds of knowledge: Theorizing practices in households and classrooms. Mahwah, NJ: Lawrence Erlbaum Associates.

Hunt, A., Nason, P. N., \& Whitty, P. (2000). Documentation as a forum and showcase in an education facility. In Issues in Early Childhood Education: Curriculum Teacher Education, \& Dissemination of Information. Proceedings of the Lilian Katz Symposium, Champaign, IL, November 5-7, 2000.

Jones, E. (2012) The emergence of emergent curriculum, Young Children, 3, 66-68.

Giovannini, D. (2001). "Traces of Childhood," in C. P. Edwards \& L. Gandini (Eds.), Bambini: The Italian approach to infant/toddler care (pp. 146-163). New York, NY: Teachers College Press.

Giudici, C., Rinaldi, C., \& Krechevsky, M. (2001). Making learning visible: Children as individual and group learners. Reggio Emilia, Italy: Reggio Children S.r.1.

Knauf, H. (2015). Styles of documentation in German early childhood education. Early Years, 35(3), 232-248.

MacDonald, M. (2007). Toward formative assessment: The use of pedagogical documentation in early elementary classrooms. Early Childhood Research Quarterly, 22, 232-242.

McLellan, S. (2010). Pedagogical documentation as research in early mathematics. The Alberta Journal of Educational Research, 56(1), 99-101.

Moje, E. B., Ciechanowski, K. M., Kramer, K., Ellis, L., Carrillo, R., \& Collazo, T. (2004). Working toward third space in content area literacy: An examination of everyday funds of knowledge and discourse. Reading Research Quarterly, 39, 38-70.

Radnor, H. (2002). Researching your professional practice: Doing interpretive research. Buckingham, UK: Open University Press. 
Reason, P. (2002). The practice of cooperative inquiry. Systemic Practice and Action Research, 15(3), $169-176$.

Rintakorpi, K. (2016). Documenting with early childhood education teachers: pedagogical documentation as a tool for developing early childhood pedagogy and practices. Early Years, 36(4), 399-412.

Saldana, J. (2016). The coding manual for qualitative researchers (3rd edition). Los Angeles, CA: Sage.

Schwartz-Shea, P., \& Yanow, D. (2012). Interpretive research design: Concepts and processes. New York, NY: Routledge.

Smith, J. K. (1992). Interpretive inquiry: A practical and moral activity. Theory Into Practice, 31(2), 102-106.

Stacey, S. (2015). Pedagogical documentation in early childhood: Sharing children's learning and teachers' thinking. St. Paul, MN: Redleaf Press.

Tarr, P. (2011). Reflections and shadows: Ethic issues in pedagogical documentation. Journal of the Canadian Association for Young Children, 36(2), 11-16.

Vakil, S., Freeman, R., \& Swim, T. (2003). The Reggio Emilia approach to inclusive early childhood programs. Early Childhood Education Journal, 30(3), 187-192.

Wein, C.A. (2008). Emergent curriculum in the primary classroom: Interpreting the Reggio Emilia approach in schools. New York, NY: Teachers College Press.

Wien, C.A., Guyevskey, V., \& Berdoussis, N. (2011). Learning to document in Reggio-inspired education. Early Childhood Research and Practice, 13(2). 


\section{Appendix A:}

Our focus group with students from the Learning in the Early Years Cohort considered the following questions (distributed in advance of the session):

What are your experiences using "in-process" documentation with the children in your class? What type of dialogue (if at all) did it generate?

What were your impressions/thoughts on its usefulness for teaching and learning (if at all)? Given that pedagogical documentation is a relatively new practice and that there are diverse understandings of this method, what is your understanding of it? AND What do you think are the essential elements or key practices associated with this method?

How is it similar to and/or different from other forms of inquiry? (For example, how might it differ from a teacher doing an observation study of her students?)

In what ways, if any, do you think pedagogical documentation might be useful for teachers, students, and parents? 


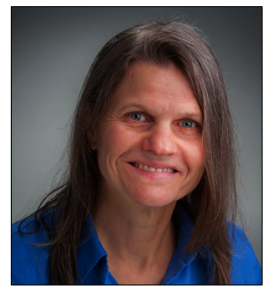

Margaret MacDonald is an Associate Professor at Simon Fraser University. Her research interests include Intergenerational Programs, Pedagogical Documentation, and Curriculum Development in Early Childhood Education. As part of her intergenerational research focus she has been working at the UniverCity Childcare centre with teachers and children to explore project-based learning and with members of the Sto:lo and Sts'ailes First Nation in British Columbia to document language and cultural revitalization. Recently she has been co-constructing philosophical understandings of new materiality theory with a research team (Drs Nathalie Sinclair, Cher Hill, Suzanne Smythe, Kelleen Toohey, and Diane Dagenais). This group, dubbed G7, has written about, and experimented with, new materiality theory and diffraction to better understand ontological epistemology.

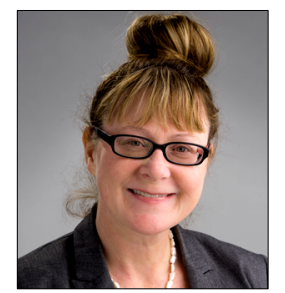

Cher Hill is an Assistant Professor of Professional Practice at Simon Fraser University. Her primary areas of expertise include practitioner inquiry, reflective practice, in-service teacher education, self-study of practice, and qualitative research methods. She works collaboratively with community groups and faculty members to develop graduate programs for practicing educators. Her current research utilizes new materialist theories to make visible the complex relations between humans and morethan-humans within educational contexts. Building on and extending Schön's notion of reflective practice, Cher has been experimenting with the notion of diffractive practice and exploring how diffractive methods might inform her pedagogy. 